\title{
LA PINTURA COLONIAL Y ROMANTICA Y ROMERO DE TERREROS
}

\section{Por Xavier Moyssén}

De los diversos temas que estudió don Manuel Romero de Terreros en relación con la historia del arte mexicano, hubo dos que le merecieron particular y constante atención: la pintura del periodo virreinal y la correspondiente al siglo xrx. En efecto, quien revise la importante bibliografía del marqués de San Francisco, encontrará una larga serie de fichas alusivas tanto a la pintura de la Nueva España como a la académica $y$ romántica del siglo XIX. Así por ejemplo, el primer trabajo publicado sobre estos temas se registra en 1914 y está dedicado a La miniatura en México y entre los últimos articulos que escribio hay uno sobre el paisajista Mateo Saldaña (1875-1951) el cual se publicó en 1965, en el número 34 de estos Anales. 1

Hombre bien informado en la historia del arte, poseedor de una extensa cultura y una fina sensibilidad, fue don Manuel Romero de Terreros; sus conocimientos respecto a la pintura del virreinato los adquirió con el trato directo y constante de las obras conservadas tanto en iglesias como en conventos, en museos públicos y en colecciones particulares; lo mismo puede repetirse parcialmente, sobre los pintores del siglo xIX y sus obras. La experiencia directa con el arte pictórico educó su gusto y le permitio ser una autoridad en la materia. En sus trabajos se muestra como un historiador dueño de una erudición en la que hace descansar tanto sus noticias como algunos de sus juicios. Romero de Terreros poseyó una conciencia viva de su posición como historiador de la pintura; todo cuanto dijo lo expresó sin falsos alardes críticos; la prudencia y la moderación, más el reconocimiento a la autoridad de los autores consultados, tales fueron las bases de donde salian sus aportaciones para la historia de la pintura mexicana, aportaciones elaboradas pacientemente, recreadas en muchas ocasiones e imprescindibles para todo trabajo de investigación que en el futuro se haga.

Los estudios de don Manuel Romero de Terreros sobre la pintura virreinal pueden agruparse en dos secciones: la primera reúne las visio-

1 La bibliografía de don Manuel Romero de Terreros, hasta 1961, fue publicada por el Instituto de Investigaciones Estéticas. Vide. Bibliografias de los investigadores, pp. 9-46, UNAM, México, 1961. 
nes de conjunto, las interpretaciones generales sobre ese arte que se produjo a lo largo de tres siglos; la sección segunda comprende los trabajos iconográficos sobre tal o cual maestro, al que estudió de manera particular y también agrupa trabajos especializados sobre los diversos temas que aparecen en los cuadros.

La historia de la pintura virreinal a partir del siglo de la conquista y hasta la fundación de la Academia de San Carlos; en dos ocasiones fue escrita por Romero de Terreros; estos estudios de conjunto aparecieron como capitulos de las siguientes obras: Historia sintética del arte colonial de México (1521-1821) y El arte en México durante el virreinato; el primer libro fue publicado en 1922 y el segundo veintinueve años más tarde, en 1951.

Para la fecha de aparición de la primera obra, no deja de sorprender el cúmulo de conocimientos y novedades que presentaba el autor en relación a sus antecesores; él fue de los primeros historiadores que dio a conocer la pintura mural de los antiguos monasterios. Con atinado criterio indicó las influencias europeas sobre la pintura virreinal y habló de las diferentes técnicas empleadas. No se olvidó de los artistas indigenas del Xvi y desechó a Rodrigo de Cifuentes, pintor apócrifo a quien se tenía por el primer pintor que pasó a la Nueva España. Los principales maestros de los siglos xvir y xvIII así como los académicos, son presentados por Romero de Terreros en una secuencia cronológica, indicando los méritos de los mismos así como las noticias de sus mejores obras y estilos. En 1922 hay una gran virulencia nacionalista en el pais, la cual ha sido propiciada por la revolución que estalló doce años atrás, pero como cada quien entiende el nacionalismo a su manera, Romero de Terreros declara que el arte virreinal "debe reputarse como el arte verdaderamente mexicano".

El capitulo sobre la pintura incluido en El arte en México durante el virreinato, es en cierta forma una recreación, ampliada considerablemente, del capítulo del mismo tema del libro anterior. El autor ofrece novedosos puntos de vista y habla de artistas no incluidos como el dominico Alonso López de Herrera a quien él identificó en una acuciosa investigación publicada en 1934. La concepción histórica de la pintura virreinal que en apretada síntesis entregó Romero de Terreros en este libro, es una introducción útil y siempre válida sobre los tres siglos de la pintura novoespañola.

No deseo pasar por alto, antes de continuar, la meritoria tarea que el marqués de San Francisco llevó a cabo al publicar en 1919 la primera 
Bibliografia de la pintura en la Nueva España; esta fuente documental la formo con ciento seis fichas, algunas de las cuales hoy resultan de un valor relativo, pero en su época constituyeron un punto seguro de partida para la investigación.

Una feliz investigación realizada en el Archivo General de la Nación, llevó a don Manuel Romero de Terreros a la localización de un legajo con documentos fechados en 1612, procedentes del Santo Oficio de la Inquisición; el legajo contiene varias listas de libros que se presentaron ante esa institución y entre ellos se encuentra la Memoria de los libros de Luis Lagarto. Con el estudio del manuscrito nuestro historiador del arte publicó un trabajo sobre La biblioteca de Luis Lagarto ${ }^{2}$ en el que reunió las noticias conocidas sobre el miniaturista de la catedral de Puebla, además de algunos comentarios referentes a las setenta y dos obras que el artista poseyó. La publicación de este documento enriqueció el panorama de la pintura virreinal del siglo xvir, pues libros como los que tenía Lagarto debieron ser comunes en los talleres de otros maestros.

El interesante cuadro anónimo de La Plaza Mayor de México en el siglo $X V I I I$, fue estudiado con esmerado detenimiento por Romero de Terreros, en un texto de erudita sabiduria en el que describe todo cuanto de interés se pintó en el cuadro: la visita del virrey marqués de Croix a la Catedral, el pueblo reunido para ver el paso de la real comitiva, el espectáculo pintoresco y bullicioso del gran tianguis, dentro y fuera del Parián; la diversidad de tipos de la sociedad capitalina, la arquitectura de los principales edificios que enmarcan la Plaza, etcétera. Para estudiar el cuadro lo dividió acertadamente en once secciones y así logró una exacta y amena descripción de esta obra "que ofrece (el) mayor interés, tanto desde el punto de vista de la expresión artística popular, como del de documento histórico..." En 1949 dio a conocer un nuevo cuadro sobre la Plaza Mayor de México; esta tela fue pintada a finales del siglo xvi por el maestro Cristóbal de Villalpando; como el artículo lo escribió a base de fotografias enviadas desde Inglaterra, en donde se encuentra el cuadro, sus comentarios poco aluden a la obra de arte en cuanto tal."

El conocedor consumado de la pintura virreinal que había en don

2 Apareció en los Memoriales de la Academia de la Historia, t. xvur, México, 1950. Hay separata.

a La Plaza Mayor de México en el siglo XVIII. Instituto de Investigaciones Estéticas, UNAM, México, 1946.

"La Plaza Mayor de México en el siglo xvn" México en el Arte, núm. 8, INBA, México, 1949. 
Manuel Romero de Terreros, le permitió tratar y difundir en artículos siempre interesantes, un número variado de temas pictóricos, tales como los "Escudos de monjas", 5 "Pinturas chinas en México", " la identificación de una serie de cuadros de José de Paéz, ${ }^{7}$ o un conjunto de pinturas murales del siglo xvi. 8

La aportación mayor que hizo en las investigaciones sobre la pintura virreinal, fue el identificar la valiosa obra del fraile dominico y pintor manierista, Alonso López de Herrera. ${ }^{\circ}$ De ningún otro maestro de la primera mitad del siglo Xvu, el siglo de oro de la pintura de la Nueva España, se tiene un trabajo monográfico semejante, tanto por las noticias biográficas que presenta como por el número de cuadros reunidos. Con fino sentido crítico el marqués de San Francisco analizó las principales características formales que había en una serie de obras anónimas, para llegar a la feliz conclusión de que eran semejantes a las de otro grupo de cuadros firmados por Alonso López de Herrera, a quien sin duda pertenecían. La identificación fue absoluta y andando el tiempo el número de pinturas del fraile ha aumentado sobre la base segura que es el estudio de Romero de Terreros.

Fiel a su gusto artístico don Manuel Romero de Terreros no mostró interés alguno hacia la pintura contemporánea de México; no sucedió asi respecto al siglo xix, pues se identificó en todas formas con el arte de la Academia de San Carlos y con la expresión romántica de sus pintores, dedicándoles una parte considerable de sus trabajos históricos. Gracias a esa identidad que guardaba con la Academia fue posible la publicación de los Catálogos de las exposiciones de la antigua Academia de San Carlos de México (1850-1898), ${ }^{10}$ él poseía una colección original de los catálogos.

Pintores como José María Velasco, el poblano Daniel Dávila, Primitivo Miranda, Felipe Gutiérrez y José Calderón, son los principales de

- Articulo publicado en El Hijo Pródigo, vol. vi, núm. 19, México, 1944.

- Apareció en las Memorias de la Academia Mexicana de la Histonia..., Mexico, 1952.

7 "José de Paéz y su 'Vida de San Francisco Solano"." En Anales del Instituto de Investigaciones Estéticas, vol. v, núm. 17, UNAM, México, 1949.

8 "El convento franciscano de Ozumba y. las pinturas de su porteria." En Anales del Instituto de Investigaciones Estéticas, vol, vı, núm. 24, UNAM, México, 1956.

- El pintor Alonso Lópex de Herrera, este primer trabajo fue editado en lujosa plaquette en 1934, por la Editorial Cultura. El estudio notablemente enriquecido con nuevas noticias y grabados, lo publicó en los Anales del Instituto de Investigaciones Estéticas, vol. Ix, núm. 34, UNAM, México, 1965.

10 Publicación del Instituto de Investigaciones Estéticas, UNAM. Serie de Estudios y Fuentes del Arte en México, vol. xiv, México, 1963. 
quienes se ocupó, bien publicando documentos sobre los mismos o artículos en los que mostraba el valor de sus creaciones pictóricas. Los pintores extranjeros que trabajaron en México, ocuparon su pluma en diversas ocasiones; en 1949 dio a conocer una parte de la obra de Daniel Thomas Egerton ${ }^{11}$ sobre el paisajista francés Barón Gros, publicó un interesante estudio en 1953.12

Dos fueron los trabajos principales que escribió el marqués de San Francisco, en relación con el arte pictórico del siglo pasado; ambos estudios están relacionados con una singular expresión del romanticismo: la pintura de paisaje. Con certero juicio supo ver el célebre historiador del arte, la unidad que hay en la escuela de pintura de paisaje que desde la Academia creara el italiano Eugenio Landesio. Tanto la obra principal del maestro, como la de sus discípulos, se dio a conocer por vez primera reunida, en Paisajistas mexicanos del siglo XIX.13 A los comentarios que dio el autor sobre los artistas incluidos, agregó los que aparecieron en los catálogos de las exposiciones anuales de la Academia, a que concurrieron. Los paisajistas presentados son los siguientes: José Jiménez, Luis Coto, Javier Alvarez, Gregorio Duraine, Salvador Murillo y José María Velasco.

Frente a la valiosa obra de los maestros mexicanos, debe verse la que aquí hizo un grupo de pintores procedentes de distintas partes de Europa y los Estados Unidos de Norteamérica; a esos paisajistas que antecedieron a los nacionales, Romero de Terreros los califico como los "descubridores del paisaje mexicano". "14 Estudio valioso y lleno de novedad por el número de pintores reunidos, noticias sobre los mismos y las reproducciones de algunas de sus obras, fue el que realizó el marqués de San Francisco para dar a conocer en conjunto, ese importante aspecto del arte en México en el siglo xix.

Todo cuanto escribió don Manuel Romero de Terreros sobre la pintura en México tanto del periodo virreinal como del siglo decimonono, debe verse en relación con la totalidad de su obra histórica dedicarla al arte, desde esa posición sus estudios sobre la pintura adquieren su propio valor.

11 Paisajes mexicanos de un pintor inglés. Editorial Jus. México. 1949.

12 El barón Gros y sus vistes de México. Imprenta Universitaria. México. 1953.

18 Edición del Instituto de Investigaciones Estéticas, UNAM, México, 1943.

14 Vease: "México visto por pintores extranjeros del siglo Xix", en Anales del Instituto de Investigaciones Estéticas, vol, vi, núm. 28, UNAM, México, 1959. El texto fue reproducido con el título: "Los descubridores del paisaje mexicano", en la revista Artes de México, núm. 28, 1959. 